\title{
Insight: the concept, the assessment and the label
}

\author{
Julian C. Hughes
}

\begin{abstract}
SUMMARY
This refreshment summarises some of the ways in which 'insight' has been understood in psychiatric practice and offers some critical thoughts about the notion.

\section{DECLARATION OF INTEREST}

None.

\section{KEYWORDS}

Insight; psychosis; phenomenology.
\end{abstract}

When used in psychiatry, the word 'insight' is technical and does not correspond precisely with day-today usage. Sims regards it as the patient's attitude to their 'illness, difficulties and prospects'. He comments: 'Any illness of some severity will alter the patient's world, and view of the world' (Sims 1988: p. 306).

Psychosis has frequently been defined by a loss of insight. Jaspers (1913), while recognising that insight occurs in dementia and other conditions (e.g. catatonia), links loss of insight to psychosis. Against this view, Lewis (1934) contends that insight cannot be used to distinguish between psychosis and neurosis because it occurs in both. He gives his own tentative definition of insight as 'a correct attitude to a morbid change in oneself' (Lewis 1934). Loss of insight can be a feature of a variety of conditions and is related to poorer quality of life, psychosocial functioning, therapeutic compliance and readmission rates (Van Camp 2017).

\section{A continuum of insight}

Marková \& Berrios (1992) suggest that insight is 'a continuum of thinking and feeling, affected by numerous internal and external variables'. This view, which allows for the possibility of 'partial insight', contrasts with the sometimes rather glib assertion that a person either does or does not have insight. They draw out a distinction made by Jaspers 'between awareness of illness, that is experiences of feeling ill or changed, and insight proper, where a correct estimate could be made of the type and severity of the illness' (Marková 1992). Marková \& Berrios (2011) further argue for 'a fundamental distinction [...] between awareness and insight', where 'awareness' is a narrower and 'insight' a broader form of self-knowledge. Jaspers also describes a polarity in the attitude of a patient to their illness: 'objective knowledge on the one hand, relating to the morbid process, and on the other comprehending appropriation of it, related to the foundations of the patient's own true existence' (Jaspers 1913; 1997 reprint: p. 426). On the one hand, there is my knowledge of my illness, which is like my psychiatrist's knowledge of it, for example I have a depression as shown by my pervasive low mood, anhedonia and loss of energy. But on the other hand, the meaning of my depression touches deeper aspects of myself and of my existence. Insight in this deeper sense is much less tangible and testable.

\section{Assessment of insight}

Nevertheless, David (1990) proposed that the assessment of insight should be standardised, regarded not as an 'all-or-nothing' phenomenon but as having three distinct overlapping dimensions: 'the recognition that one has a mental illness, compliance with treatment, and the ability to relabel unusual mental events (delusions and hallucinations) as pathological'. Four questions can help to establish the degree of insight:

1 Is the person 'aware of phenomena that other people have observed'?

2 If so, does the person 'recognise that these phenomena are abnormal'?

3 If so, does the person "consider that they are caused by mental illness'?

4 If there is acceptance of illness, does the person think he or she needs treatment? (Gelder 1989; p. 33).

A number of standardised measures of insight have been developed, including an assessment of 'cognitive insight', which looks at the cognitive processes required for people to evaluate their experiences, dividing them into self-certainty and self-reflectiveness scales (Beck 2004). In a review of cognitive insight, Van Camp (2017) suggests that these components should be studied separately because, for instance, higher levels of self-reflection
Julian C. Hughes is RICE Professor of Old Age Psychiatry at the University of Bristol Medical School and also works at the Research Institute for the Care of Older People (RICE) in Bath. He is an honorary consultant at the Royal United Hospitals Bath and with the Avon and Wiltshire Mental Health Partnership NHS Trust. He is currently deputy chair of the Nuffield Council on Bioethics, UK.

Correspondence Professor Julian C. Hughes, The RICE Centre, Building 8, Royal United Hospital, Combe Park, Bath BA1 3NG, UK.

Email: julian.hughes@bristol.ac.uk

\section{Copyright and usage}

(C) The Royal College of Psychiatrists 2018 
can be associated with depressive mood, whereas we normally think of better insight as good. 'Insight' remains a problematic notion, suggesting a number of different concepts that are hard to capture, so that 'lack of insight' can reflect various psychopathological and neuropathological states or processes.

\section{Aspects of insight}

The variety of aspects of insight is reflected in a distinction between intellectual and emotional insight: the violent person and the person dependent on alcohol know (intellectually) that they should resist their inclinations but cannot change their emotional responses. Similarly, but in connection with cognitive impairment, people living with dementia demonstrate the mnemic neglect effect (MNE), selectively forgetting highly negative, self-referent statements, perhaps as a manifestation of repression, but also showing lack of insight (Cheston 2018).

\section{'Lack of insight' as a label}

It is important to recognise that 'lack of insight' is a label that positions people in a certain light. Once it is declared that a person 'lacks insight' he or she is regarded as having a significant mental illness, which seamlessly calls into question decisionmaking, judgements and abilities, while raising worries about risk-taking and safety. Having a mental illness itself changes the basis on which judgements about that illness are made; a depressed person may well make depressed judgements. Nonetheless, to recall Jaspers, 'The constant search for meaning, interpretation and inclusion [...] does not immediately signify lack of insight into the illness' (Jaspers 1913; 1997 reprint: p. 427).

\section{References}

Beck AT, Baruch E, Balter JM, et al (2004) A new instrument for measuring insight: the Beck Cognitive Insight Scale. Schizophrenia Research, 68: 319-29.

Cheston R, Dodd E, Christopher G, et al (2018) Selective forgetting of selfthreatening statements: mnemic neglect for dementia information in people with mild dementia. International Journal of Geriatric Psychiatry, 33: 1065-73.

David AS (1990) Insight and psychosis. British Journal of Psychiatry, 156: 798-808.

Gelder M, Gath D, Mayou R (1989) Oxford Textbook of Psychiatry (2nd edn). Oxford University Press.

Jaspers K (1913) Allgemeine Psychopathologie. Reprinted in part (1997) in English as General Psychopathology: Vol. I (trans J Hoenig, MW Hamilton). Johns Hopkins University Press.

Lewis A (1934) The psychopathology of insight. Journal of Medical Psychology, 14: 332-48.

Marková IS, Berrios GE (1992) The meaning of insight in clinical psychiatry. British Journal of Psychiatry, 160: 850-60.

Marková IS, Berrios GE (2011) Awareness and insight in psychopathology: an essential distinction? Theory \& Psychology, 21: 421-37.

Sims A (1988) Symptoms in the Mind: An Introduction to Descriptive Psychopathology. Baillière-Tindall.

Van Camp LSC, Sabbe BGC, Oldenburg JFE (2017) Cognitive insight: a systematic review. Clinical Psychology Review, 55: 12-24. 